\title{
ИЗМЕНЕНИЯ УРОВНЯ ЗАТРАТ НА НИОКР ПРОМЫШЛЕННОГО СЕКТОРА В ЭКОНОМИКЕ РФ
}

\author{
(c) 2020 Салькина Альфия Ринатовна \\ кандидат экономических наук, доцент \\ Самарский государственный экономический университет, Россия, Самара \\ E-mail: alya-0508@yandex.ru
}

В статье дана характеристика развития сектора НИОКР в промышленной сфере Российской Федерации. Важнейшим фактором модернизации отечественного промышленного сектора является развитие и усовершенствование НИОКР на глобальном уровне. Эта задача является приоритетной в экономической политике, так как именно на основе этих показателей, в том числе, формируется общемировой рейтинг экономического влияния всех развитых и развивающихся стран. Проанализирован уровень расходов в данный сектор промышленности с точки зрения сравнения с мировыми лидерами в сфере научных разработок.

Ключевые слова: промышленный сектор, НИОКР, динамика развития Российской Федерации, уровень развития сферы научных исследований, мир в сфере НИОКР.

В современных условиях российской экономики, очень важно обращать внимание на такие крупные «объекты» как промышленность. На фоне среднемировой величины доли внутренних расходов в промышленном секторе экономики на НИОКР в ВВП неизменно падают, в следствие чего, сокращается объем инвестирования в России. Наблюдается тенденция снижения самого интеллектуального потенциала промышленного сектора в России. Причиной этому мог послужить ряд существенных факторов, а именно уменьшение численность специалистов, которые работают в секторе НИОКР (-9\% за последнее десятилетие). В связи с чем, прослеживается встречный тренд повышения уровня трудоемкости, который подразумевает существенные затраты на персонал НИОКР в структуре инвестиций во внедряемых проектах (+ 7\% к стоимости). Прослеживается объективно выраженная трансформация российского сектора научных и исследовательских разработок [1].

1) Существенно развивается участие ВУЗов в сфере инновационных процессов (+15\% за последние десятилетия);

2) Понижение роли специализированных НИИ (-25\%);

3) Растет сфера участия государства в реализации научно-технических проектов (+7\%);

4) Повышается участие научных подразделений промышленных предприятий (+2\%).

Изменение влияния субъектов подразделений, их взаимодействия и экономики требует инновационного подхода в сфере управления, который позволит увеличить эффективность и, соответственно, саму производительность процессов НИОКР.

Количество вливаемых затрат в НИОКР в добавленной стоимости инновационной продукции можно определить через ее наукоемкость, или другими словами - уровень технологичности всех отраслей. Именно ее технологические лидеры реально смогут оценить необходимый уровень затрат на инновационное исследование и разработку. Проведя аналиту в уже поставленных на производство промышленных проектах, наблюдается разброс процентного соотношения в зависимости от размера самого производства. Так, в высоко и $8 \%$ средне-технологичных отраслях промышленности, этот показатель варьируется от 5-21\% по отношению к цене производимого продукта, что составляет больше $18 \%$ в добавленной стоимости. Такие значения определены в качестве основных в среднесрочной интерпретации планирования модернизации национального сектора экономики, отражённые в федеральной целевой программе «Исследования и разработки по приоритетным направлениям развития научно-технологического комплекса России на 2014-2020 годы».

Ресурсы ФЦП, которые служат для создания и спонсирования инновационных разработок, дающих, в свою очередь, выход на модульные разработки и товары по тем технологическим направлениям, которые определяются как наи- 
более важные, включая и развитие новейшей инфраструктуры. По факту объем со финансирования ФЦП в 2016 году составил около 300 млрд. рублей [2]. Вместе с тем, не был проработан анализ тенденций развития данного сектора в экономике страны. Между тем, если рассматривать конкурентоспособность такого сектора на мировой арене, именно развитие национальной инновационной системы (табл. 1) является первоочередным индикатором сектора научно исследовательских и опытно-конструкторских разработок и только во вторую - институциональные показатели [3].

Приведенная в табл. 1 динамика, объясняется долей внутренних расходов (в ВВП) и численностью занятых в секторе НИОКР (в общем объеме населения). Такого рода стагнация происходит из за быстрого развития глобальных мировых трендов. Так, за последние 8 лет наблюдается динамичный и планомерный рост доли внутренних расходов на НИОКР в ВВП ЕС $(+0,25 \%)$, что обосновывается стабильным государственным инвестированием в стратегически промышленные объекты, и активное привлечение сторонних инвесторов в такие проекты.

Особо выигрышным выглядит в такой динамики Австрия, чей прирост расходов на НИОКР с 2008-2016 гг. составил более 0,7\%, что достаточно весомо, в сравнении с Италии, где прирост за этот же период составил всего 0,18\%.

Безусловно, необходимо отметить лидеров по внутренним расходам на сектор НИОКР- Японию, где затраты начинаются с 3,309\% (в доле ВВП страны на период 2008 г.) предпосылками такому явлению могли служить активно развивающийся научный сектор в конструкторской сфере и большое вливание государственного бюджета именно на разработки молодых ученых с перспективными «start apр» предложениями.
Это можно заметить и по рынку сбыта, где азиатские страны (стоит упоминуть и Китай) повсеместно внедряют функционирующие разработки в научно-исследовательской сфере.

Затраты на НИОКР в инновационно развитых странах методично показывают положительную динамику роста, что вызвано высоким уровнем научно-технического развития стран. В России расходы сохраняются на уровне 1\% (по результатам на 2016г.), при незначительной прогнозной положительной динамике роста величины ВВП в среднесрочной перспективе. Именно это можно обозначить одной из главных проблем сложившегося в России промышленного сектора, которая, несомненно, требует должного внимание со стороны правительства РФ. Необходимы кардинальные меры по реализации инновационной стратегии роста промышленности, которые внесли бы важные изменения в рост ВВП.

Помимо всего прочего, наблюдается яркая тенденция, направленная на спад количества специалистов, задействованных в сфере НИОКР, особенно на контрастной динамике постоянного повышения такого коэффициента в странах Евросоюза (рис. 1).

Если рассуждать про абсолютное выражении (34) численность инженерного и исследовательского персонала цикла НИОКР, то начиная с 2015 год их численность составила 813,2 тыс. чел (что составляет более 50\%), из них 391,1 тыс. человек, функционирующих на базе прикладные НИР (более 45\%). При рассмотрении затрат на НИОКР в ВВП в лидеры также выбивают Израиль, чей показатель за 2017 г. превысил 4,25\%. Далее Корея - 4,24\%. И замыкает США и Китай.

Такого рода негативная тенденция наблюдается, в первую очередь, из-за недостатка уровня квалификации работников и специалистов в научной сфере, и востребованности потен-

Таблица 1. Конкурентоспособности РФ по инновационным факторам по данным WEF Обозн.: М - место в мировом рейтинге; П - позиция (1-7, 7-макс.).

\begin{tabular}{|c|c|c|c|c|}
\hline \multirow{2}{*}{ Факторы } & \multicolumn{2}{|c|}{2012} & \multicolumn{2}{|c|}{2017} \\
\hline & M & $\Pi$ & M & $\Pi$ \\
\hline \multicolumn{5}{|l|}{ Инновационный фактор в экономике: } \\
\hline (институциональные) возможности для инноваций; & 38 & 3,5 & 78 & 4,0 \\
\hline качество научно-исследовательских организаций; & 60 & 3,8 & 46 & 4,2 \\
\hline Внутренние расходы предприятий на НИОКР; & 61 & 3,1 & 66 & 3,3 \\
\hline сотрудничество университетов и промышленности в НИОКР; & 75 & 3,5 & 46 & 3,7 \\
\hline государственная закупка передовых технологий и продуктов; & 99 & 3,3 & 68 & 3,3 \\
\hline Доступность интеллектуального потенциала (ученых и инженеров). & 72 & 4,0 & 58 & 4,1 \\
\hline
\end{tabular}




\section{ДОЛЯ ВНУТРЕННИХ РАСХОДОВ НА НИОКР В ВВП, \% ВВП}

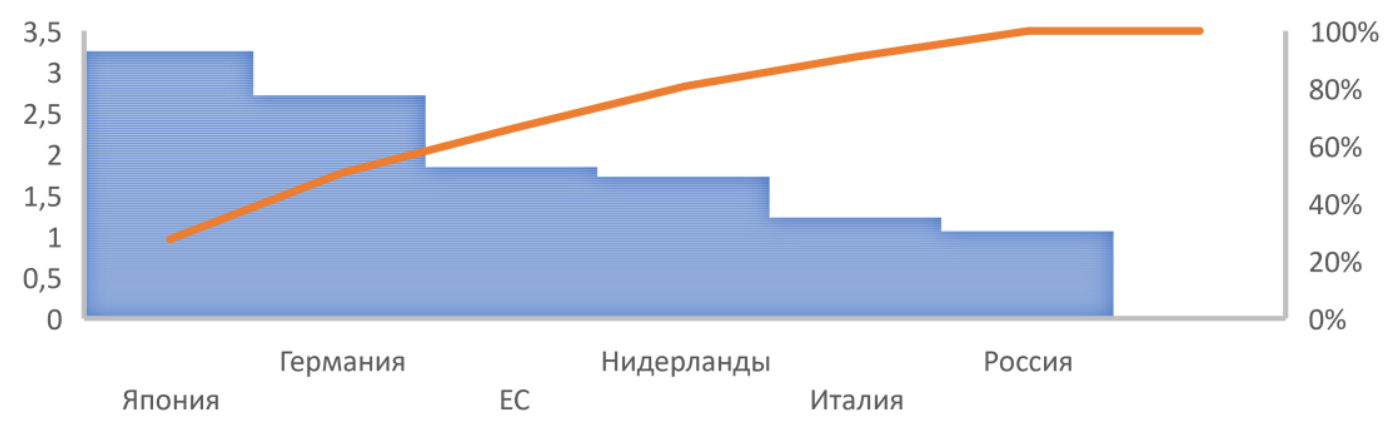

Puc. 1. Данные анализа позиции промышленной сферы НИОКР России и мировых лидеров. Интерпретировано по базам данных OECD, 2018 г. [4]

циальных трудовых ресурсов в данном секторе. Проанализировав данные, можно четко выявить основную проблему, которая в целом «тормозит» развития НИОКР - это, безусловно, слабая инвестиционная программа именно внутри страны и на уровне государственной поддержки и субсидий на развитие НИР. При этом, нужно разграничивать понятие государственно поддержке в этой сфере, так как речь идет именно о внедрении (о конечном этапе) на производство новых разработок, их дальнейшее применение. В 2018г, Россия по величине внутренних расходов на НИОКР, учитывая покупательской способности, вошла в десятку. Но по удельным затратам на этот сектор промышленности, и уровню ВВП, замыкает третий десяток.

Рассуждая о занятости научных сотрудников в сфере НИОКР, то в расчете на одного исследователя, она занимает 47 место в мировой рейтинге (93 тыс. дол. в год). Но по уровню масштаба занятости в науке, России входят в двадцатку лидеров (428,9 тыс. чел за 2016 г.) [5].

Необходимо отметить, что на базе этой аналитики, можно с уверенность рассуждать возможности развития организационной модели инновационного процессе научных разработок, что приведет к общему росту коэффициента развития отечественного промышленного сектора. Развития на этапе постановке на производство бужет происходить только с учетом планомерного контроля в специализированных секторах на каждом этапе, включая институциональное развитие национального сектора рынка ИОС [2].

Одной из положительных черт развития научно-исследовательских и опытно конструк- торских разработок за последнее десятилетия является уход от традиционной (устаревшей) модели развития промышленного сектора и внедрения новых технологий. Кластерный подход стал преобладающим в данном виде деятельности, что в свою очередь сказывается на стабильной динамике роста. На данный момент большинство предприятий стали привлекать в новым разработкам новые источники для взаимодействия - ВУЗы, конструкторские бюро, и, что немало важно, Start-up проекты российских молодых ученых. В промышленной сфере разработок появилось понятие «аутсорсинг», которое позволяет экономить время и расходы на этапах разработок и внедрения инновационных подходов.

По прогнозам РАН, основной задачей в экономической сфере бужет также является увеличения проектных достижений производственных программах на фоне мировой величины расходов на НИОКР; создание новых платформ для более модифицированного развития этапах «внедрения» и «прототипирования» [6]. Таким образом, продемонстрированы инновационные направления, позволяющие отслеживать состояния энергетике и энергосбережении. Именно они определены важнейшими факторами, регулирующие уровень вложения в НИОКР указом Президента РФ от 1 декабря 2016 г. № 642 «О Стратегии научно-технологического развития Российской Федерации». Следовательно, можно указать на основные и имеющие большое влияние на инновационный сектор точки роста национального развития научных исследований и разработок. 


\section{Библиографический список}

1. OECD: Science, Technology and Industry Outlook.- OECD, 2017.

2. Хлебников К.В. Сопоставительный анализ инвестирования в человеческий капитал в интересах инновационного развития высокотехнологичных предприятий. М.: Вопросы экономики и права, № 112016.

3. The Global Competitiveness Report 2016-2017. World Economic Forum, 2017.

4. OECD Main Science and Technology Indicators Volume 2017 Issue 2, OECD Publishing, 2018.

5. Ивлеев Г. Развитие сферы интеллектуальной собственности в свете «Основных направлений деятельности Правительства РФ».: Интеллектуальная собственность. ПРОМЫШЛЕННАЯ СОБСТВЕННОСТЬ № 3 / 2019

6. Прогноз научно-технологического развития Российской Федерации на долгосрочную перспективу (до 2030 г.). Концептуальные подходы, направления, прогнозные оценки и условия реализации.- М.: РАН, 2008. 